\title{
Tarefas de desenvolvimento do adulto idoso'
}

\section{Old aged developmental tasks}

\author{
Geraldina Porto WITTER ${ }^{2,3}$
}

\begin{abstract}
Resumo
As tarefas de desenvolvimento são básicas em cada seqüência do ciclo de vida. Há uma expectativa social de que as pessoas em cada seqüência cumpram com êxito suas tarefas. Na última parte do ciclo de vida também a pessoa idosa tem tarefas de desenvolvimento a cumprir de modo a ser feliz e ter qualidade em sua vida. As tarefas do idoso são objeto de descrições e considerações. Pesquisas sobre as tarefas do idoso são importantes devido à necessidade de informações sobre o assunto.
\end{abstract}

Palavras-chave: comportamento social; desenvolvimento humano; fases do ciclo de vida.

\begin{abstract}
The developmental tasks are essential in every sequence of life cycle. There is a social expectation about people's performance in each sequence and its tasks. In the last part of the life cycle, there are developmental tasks the old aged person has to face in order to be happy and guarantee life quality. The old people's tasks are object of descriptions and considerations. Researches about the old aged tasks are considered important because the need of this subject information.
\end{abstract}

Key words: social behavior; human development; life cycle stages.

Havighurst (1953), um dos mais notáveis psicólogos do desenvolvimento humano, insatisfeito com os modelos e teorias do desenvolvimento prevalentes nos anos quarentas e cinqüentas do século XX, realizou só ou em colaboração com autores de países diversos uma série de pesquisas sobre o que denominou o ciclo de vida. O ciclo de vida (life span) começa com a concepção e termina com a morte. Ele considerava que as propostas de desenvolvimento então vigentes ou eram predominantemente alicerçadas nas mudanças biológicas ou se centravam em aspectos psicológicos específicos (cognitivos, emocionais, sexuais e morais), não enfocando, com base em pesquisas sólidas, o desenvolvimento humano como um todo. Além disso, para os modelos dominantes a tendência era considerar que o desenvolvimento praticamente se completava na adolescência (às vezes antes dos quinze anos) ou começo da juventude. Os dados de pesquisas não confirmavam essas restrições e mostravam a

1 Texto original, parcialmente financiado pela FAPESP (Processo nº3/11788-6),

2 Professora Doutora, Programa de Pós-Graduação em Psicologia, Centro de Ciências da Vida, Pontifícia Universidade Católica de Campinas. Av. John Boyd Dunlop, s/n, Prédio Administrativo, Jd. Ipaussurama, 13060-904, Campinas, SP, Brasil.

3 Professora Doutora, Universidade de Mogi das Cruzes. Mogi das Cruzes, SP, Brasil. E-mail: <pwitter@umc.br>. 
insuficiência desses olhares. Além disso, as propostas tendiam a ignorar ou a minimizar o contexto cultural e histórico em que ocorria o desenvolvimento humano.

Adotando uma posição de integração que apenas se esboçava na Psicologia dos anos cinqüenta do século XX, ele propôs um novo modelo para o estudo do desenvolvimento humano ao longo do ciclo de vida.

Realizou pesquisas em todos os continentes com vários pesquisadores de diversos países. Suas pesquisas no Brasil enfocaram principalmente as populações de Recife, São Paulo, Rio de Janeiro, Curitiba e Porto Alegre.

Com base em suas pesquisas e de seus colaboradores, bem como nos trabalhos de outros com outros enfoques, estabeleceu que era adequado um modelo biopsicossocial que viabilizasse integrar criticamente os dados das mais diversas origens teóricas. Sugeriu proposta de etapas de desenvolvimento que se caracterizam por tarefas biopsicossociais que a pessoa deve cumprir em cada uma delas para ter êxito (Havighurst, 1953; Bischof, 1976). São tarefas comuns naquela etapa em cada região do mundo, todavia há características peculiares em decorrência do contexto sócio-histórico e da história de vida das pessoas.

A ampliação da duração do ciclo de vida gerou um crescimento na população idosa - o seguimento da humanidade em mais rápido crescimento nas últimas décadas (Chawla, 2003), criando problemas devido à falta de preparo da sociedade nos seus vários setores, lembrando-se aqui o impacto nos sistemas de saúde e de aposentadoria (Johansson et al., 2001). Nesse contexto é importante rever as referidas tarefas.

\section{Tarefas de desenvolvimento do idoso}

Entende-se por tarefas de desenvolvimento aquelas que a pessoa deve cumprir para garantir seu desenvolvimento e seu ajustamento psicológico e social. São tarefas com as quais a pessoa satisfaz "suas necessidades pessoais de evolução e para garantir o próprio desenvolvimento e manutenção de padrões sociais e culturais específicos" (Melo, 1981, p.21). Mais ainda, além de garantir a formação e a atuação do cidadão, devem dar base de sustentação para o progresso (pessoal e social) e bem-estar humano.

Pfromm Netto (1976) considera que as tarefas de desenvolvimento são como "lições" que a pessoa deve aprender ao longo de sua existência para se desenvolver satisfatoriamente e ter êxito na vida.

As tarefas não são estanques em cada etapa embora algumas sejam preferencialmente típicas dessa ou daquela fase. Em cada fase todas se relacionam entre si e o prejuízo ou déficit em uma tarefa pode comprometer outras no mesmo período ou em período futuro.

Na infância/meninice a pessoa tem como tarefa básica dominar a leitura e a escrita, que servirão de instrumentos para sua independência, para uma comunicação mais ampla e efetiva, para viabilizar posteriormente melhores escolhas de formação e profissionalização, entre outras possibilidades melhores. Infelizmente, contingências socioculturais e econômicas muitas vezes impossibilitam o cumprimento dessa tarefa no momento adequado do ciclo da vida. Muitas pessoas sequer conseguem cumpri-la ao longo da vida, outras só a irão cumprir mais tarde, na adolescência, na vida adulta ou mesmo na velhice. Certamente isso prejudica o cumprimento satisfatório de outras tarefas, representando muitas vezes exclusão, perda de auto-estima, redução na sua qualidade de vida, além de prejuízo para a sociedade como um todo.

Dessa forma, as tarefa da juventude se relacionam com as da fase anterior e se prolongam nos períodos subseqüentes e assim sucessivamente.

Subjacente à proposta de tarefas de desenvolvimento há um esforço de unificação de várias concepções do desenvolvimento, desde que passíveis de comprovação empírica. Também está implícita uma premissa interacionista bem demarcada e que posteriormente seria desenvolvida em várias propostas, como no enfoque ecológico e mais recentemente no trabalho de Psicologia Ambiental. Wagman e Miller (2003) trabalham nesse último enfoque e lembram ser inadequado pressupor que o desenvolvimento seja geneticamente programado. Ele decorre de uma ampla troca entre organismoambiente, formando uma rede de relação da concepção à morte, perpassando todo o ciclo de vida. 
A unidade de análise é justamente a relação organismo-ambiente em seus múltiplos níveis na rede de relações.

Uma pesquisa focando a relação organismoambiente em idosos foi realizada, em 2001, por Johansson, Grand, Plamin, Peterson, Ahen, Berg e McClearn, junto a 420 octogenários (idade média de 83,2 anos) em busca de conhecer o lócus de controle de saúde e com 141 pares de gêmeos (71 idênticos e 70 fraternos) para detectar as contribuições relativas da genética e do ambiente nas crenças sobre controle da saúde. Os autores concluíram por meio dos dados encontrados que o construto de lócus de controle de saúde é multidimensional entre os idosos; que o fator estrutura é similar ao encontrado em outras idades; que não há evidência clara de relação entre crenças sobre lócus de controle e saúde; que há uma indicação de serem mínimas as influências genéticas em duas escalas (mudança/interna) e só uma influência mínima quanto ao poder dos outros no lócus de controle. Sugerem que os próximos estudos se voltem mais para as fontes ambientais.

Havighurst (1953) propôs como períodos marcantes da vida adulta: idade adulta inicial (dos 18 aos 30 anos), idade adulta média ou maturidade (dos 35 aos 65 anos) e idade adulta final também denominada maturidade posterior ou velhice. Principalmente essa última será enfocada neste trabalho.

Apenas para contextualizar as tarefas da velhice retomam-se aqui as da etapa anterior do processo de ser, ou as tarefas do adulto maduro, que são: ter responsabilidades cívicas e sociais, estabelecer e manter um padrão econômico de vida, ajudar os adolescentes a serem futuros adultos responsáveis e felizes, desenvolver atividades adultas de lazer, relacionamento com esposo(a) como pessoa, aceitar e ajustar-se às mudanças físicas da meia-idade e ajustar-se aos pais idosos.

Ao dar conta das tarefas de adulto a pessoa está concomitantemente se preparando para viver bem a velhice, cuidando de adquirir e de manter comportamentos que facilitarão ter boa qualidade de vida nesse período (Neri \& Freire, 2000). Os idosos têm tarefas que diferem das demais idades por seu caráter funcional, por serem mais defensivas e preventivas, mas isso não é razão para se ter uma perspectiva negativa da velhice. A proposta de Havighurst (1953) é mais condizente com uma perspectiva que mais recentemente vem sendo denominada de Psicologia Positiva, ou seja, valoriza os aspectos saúdaveis, os pontos que podem contribuir para a realização pessoal, para a alegria e a satisfação em viver.

Evidentemente devem-se conhecer as variáveis, as estratégias que facilitam ou dificultam o êxito da pessoa no cumprir as tarefas. Estudar as pessoas que foram bem sucedidas pode fornecer subsídios para ajudar outras a conseguirem o mesmo resultado. Essa é uma perspectiva positiva.

As tarefas dos idosos são: ajustar-se ao decréscimo de força física e saúde; ajustar-se à aposentadoria e à redução de renda; ajustar-se à morte do(a) esposo(a); estabelecer filiação a um grupo de pessoas idosas; manter obrigações sociais e cívicas e estabelecer arranjos físicos satisfatórios para viver bem a velhice.

No caso da tarefa de ajustar-se às perdas biológicas decorrentes do envelhecimento do corpo é importante lembrar que com a idade ocorrem mudanças físicas diversas, perda de força e de resistência, aumento da susceptibilidade às doenças e redução das propriedades de auto-reparo do organismo. As pessoas ficam mais expostas a acidentes, a doenças infecciosas, perdem acuidade dos sentidos e, por vezes, ficam inválidas. É preciso aprender a conviver com essas limitações e agir de modo a torná-las mínimas ou reduzirIhes o ritmo. Os aspectos biológicos e médicos são relativamente bem conhecidos, especialmente da década de 80 para cá, todavia o mesmo não ocorre com o modo como as pessoas se ajustam às limitações (Birren, 1980). Há que se lembrar a importância do autocontrole (especialmente o emocional), da auto-eficácia, que os limites biológicos são também modelados por variáveis sociais, pelo estilo de vida, podendo os idosos ser auxiliados por programas preventivos de cunho psicoeducacional e por mudanças na própria sociedade. Além disso, atualmente um bom atendimento médico vem garantindo boas condições de saúde.

Um exemplo de dificuldade para aceitar limitações é a encontrada por alguns idosos para pararem de digirir quando aconselhados por médicos, enfermeiros, psicólogos e familiares, em decorrência de suas limitações físicas e de saúde. 
Johnson (2002) pesquisou, em um grupo de idosos (71 a 91 anos) residentes em comunidades rurais de 225 a 8700 pessoas, as razões pelas quais continuavam a dirigir mesmo tendo sido desaconselhados a fazê-lo devido ao declínio físico. Verificou que os pesquisados não sentiam que as condições físicas fossem inadequadas para a tarefa, por valorizarem sua independência e por temerem o isolamento se não pudessem dirigir. A autora sugere a necessidade de um trabalho junto aos idosos para que possam aceitar a limitação e aprender outras estratégias que assegurem a manutenção da liberdade e evitem a solidão.

Evidentementeé um problema de ordem pessoal que pode requerer uma orientação psicológica. Mas é também um problema comunitário e como tal devem ser propostos programas de prevenção e de apoio e preparo de idosos para pararem de dirigir quando suas limitações físicas assim recomendarem.

Lembrando que entre as variáveis que podem gerar estresse e depressão em idosos estão as que eles referiram no estudo de Johnson (2002). Kraaij e Garmefski (2002) verificaram em sua pesquisa que para evitar a depressão é necessário dispor de suporte social e aprender estratégias de auto-eficácia para enfrentar o estresse e a depressão. Afirmam que desenvolver programas de prevenção e intervenção com idosos implica ensinar-Ihes estratégias de adaptação e ajudálos a desenvolver seus recursos de enfrentamento.

Com a aposentadoria, na maioria dos casos, a pessoa precisa reajustar seus padrões de vida, pois passa a contar com renda menor. Muitos começam um novo emprego ou mesmo um novo trabalho, outros gostariam de fazê-lo, mas já não contam com condições físicas, aceitabilidade no mundo do trabalho ou não se prepararam para tanto. É necessário redimensionar seus gastos em um período em que a necessidade de dinheiro para a saúde tende a crescer.

A falta de preparo para a aposentadoria e o não envolvimento em atividades de lazer podem levar os idosos a comportamentos inadequados e de risco, sendo que isso pode passar despercebido pelos profissionais da saúde (médicos e enfermeiros) que os atendem, como verificaram Aalto, Pekuri e Seppae (2002) e Rush Urbanoski e Allen (2003) entre os participantes médicos.
É precário cuidar não apenas do aspecto biológico, pois outras variáveis estão em jogo, e correse o risco de tomar a parte pelo todo.

Ao longo de um casamento, os casais estabelecem relações entre si e cada um tem o papel de amortecedor para o outro nos eventos negativos da vida. Também as relações parentais desenvolvem esse mesmo papel ao longo dos anos. Esses dois tipos de relação estão presentes no controle da depressão em idosos. É particularmente importante a atuação do companheiro ou da companheira, que parece ser um mecanismo protetor quando o idoso tem que enfrentar um evento negativo, como Kraaij e Garnefski (2002) verificaram em sua pesquisa. Assim sendo, programas que otimizam essa relação podem prevenir e auxiliar na intervenção nas relações entre casais ao longo de suas vidas. Mas deve-se cuidar também de prepará-los para a tarefa de sobreviver ao par.

Com a aposentadoria o idoso passa a ter mais tempo livre, podendo dedicar-se a atividades físicas e de lazer. Mas há perdas econômicas associadas que podem dificultar as duas coisas. Ongs e instituições diversas oferecem atividades praticamente sem custos, mas cabe estimular os idosos a buscar nelas o apoio necessário. Isto pode ser de valia para cumprir outra tarefa que é a de associar-se a pessoas de sua própria idade.

É possível estimular idosos a procurarem formas diferenciadas de lazer, com as quais já devem se ocupar nas fases anteriores. As atividades de lazer cognitivo são importantes para prevenção da flexibilidade intelectual tanto do idoso que está na ativa como daquele que se aposenta. Elas podem ter baixo custo, como é o caso da leitura, e ter um forte impacto no funcionamento do intelecto e no prazer (Schooler \& Mulato, 2001). Além disso, a leitura tem o poder de fazer progredir socialmente, preservar a memória e evitar o declínio cognitivo, como mostrou a pesquisa de Manly, Toreradji, Tang e Stern (2003) com idosos não dementes, de várias etnias, em estudo longitudinal de quatro anos.

Também aumenta a probabilidade da perda do esposo(a), requerendo arranjos físicos, mudanças no estilo de vida e um controle emocional diferenciado. As atividades cívicas, sociais e de lazer podem ser de grande ajuda nos ajustamentos emocionais necessários. 
Especialmente em decorrência das limitações físicas e da perda do(a) companheiro(a), na vida do idoso devem ser introduzidos novos arranjos para que ele possa viver bem e seguro.

Pelo já explicitado, a perda do par pode trazer associadas ao aspecto afetivo outras dificuldades. Por exemplo, passar a viver só é possível quando há condições físicas e psicológicas para isso. Entretanto, sem condições de continuar só em seu lar, a pessoa pode ter de ir morar com algum parente (filhos, irmãos ou outros), o que implica a perda de seu espaço e a integração de um outro meio de convivência. Em alguns casos, o idoso poderá necessitar ir viver em algum tipo de abrigo. São muito grandes as mudanças que podem ocorrer na vida do membro do casal que sobrevive. Raramente as pessoas estão preparadas ou estabeleceram planos para essa situação, o que certamente torna a situação mais difícil e penosa. Enquanto estão juntos podem planejar, prever, organizar-se para facilitar o prosseguir na caminhada para o que está fadado a continuar vivendo. A manutenção da atenção e o envolvimento em outras tarefas podem ser de grande valia para evitar depressão e solidão. Mas moradia e sobrevivência financeira precisam ser previstas.

A tarefa de estabelecer e manter-se filiado a grupos de idosos das mais diversas naturezas garante ao idoso boas condições de saúde psicossocial. Entre esses grupos estão os religiosos, os cívicos, os políticos, os de turismo, os de ginástica e os de lazer. Clubes, Ongs, universidades, sindicatos e outras entidades têm se dedicado a esse aspecto. É preciso educar-se para isto e orientar os idosos nessa busca de acordo com suas características pessoais e motivação.

Não é por ser idoso nem pelo fato de a lei dispensar do voto que o cidadão está livre ou pode descuidar-se de suas obrigações sociais e cívicas, da formação de novas gerações, de apoiar campanhas para a melhoria da qualidade de vida de todos. É preciso, para o bem da sociedade, que sua experiência de vida seja transmitida e assimilada não só pela sua família, mas também pela sua comunidade. Os idosos podem colaborar como paraprofissionais nas escolas, nos hospitais, nos clubes, nas ruas, nas igrejas etc.

Certamente a base biológica é muito relevante, com a idade muitas vezes surgem problemas de saúde que limitam as possibilidades de locomoção com segurança, surgem problemas cardíacos, a família nuclear fica reduzida. Há necessidade de arranjos nas moradias, tais como evitar escadas ou ter cuidados especiais na construção das mesmas; arranjos nos banheiros e áreas de serviço; evitar casas muito grandes e que exijam muito trabalho quando não há recursos para pagar serviçais. É importante ter condições de residência que garantam privacidade, silêncio, proximidade de parentes, amigos e igreja, proximidade de transporte e de locais de compras e de lazer. Mas cada caso tem suas peculiaridades e devem ser estudadas as melhores formas de garantir o cumprimento dessa tarefa sem sentimentos de isolamento, perdas profundas, insatisfação etc.

Para estabelecer arranjos físicos compatíveis com as necessidades do idoso é necessário contar com dados de pesquisas dos possíveis arranjos do ambiente que Ihes garantam maior segurança. Aqui a Psicologia Ambiental pode ser de grande valia.

Também é importante contar com programas eficientes que os informem sobre o que e como mudar o ambiente e seus comportamentos. Esses programas podem ter complexidades diversas, mas devem ser avaliados quanto a sua eficiência.

Exemplo de pesquisa de avaliação de programa é o trabalho realizado por Sweeney e Chiriboga (2003) com um programa de multimídia testado com 126 voluntários, de 55 a 99 anos, comparando três grupos aleatoriamente constituídos. Um grupo submeteu-se ao programa de multimídia, outro à leitura de um folheto e um grupo não recebeu instrução alguma. Aplicaram um pré-teste e vários pós-testes (em momento subseqüentes). Só o grupo exposto ao programa de multimídia melhorou seu conhecimento e mostrou muita satisfação com o programa.

Nesse contexto, vale lembrar que vem crescendo o número de idosos que vivem sozinhos, o que tem sido considerado um indicador de saúde, mas também de situação que pode ser de grande fragilidade. A valorização positiva ou negativa do viver só, segundo Lichtenberg, MacNeill, Lysack, Bank e Neufeld (2003), embora possa refletir padrões da comunidade, indica a diferença de estudos realizados com idosos normais ou com amostras estabelecidas clinicamente.

Algumas condições devem ser levadas em conta para os idosos poderem viver só, tais como engenharia do ambiente interior, apoios sociais diversos, as próprias 
condições físicas, estar ou não em processo de recuperação de algum problema de saúde e principalmente suas condições psicológicas. É importante rever as práticas sociais assumidas em relação aos idosos que tendem muitas vezes a fortalecer uma visão negativa dos mesmos, como incapazes, como analisa Santos e Almeida (2002), e algumas práticas de exclusão que conduzem ao isolamento. Certamente essas práticas não dão o apoio necessário para que o idoso desenvolva suas tarefas.

Witter e Maria (2005) verificaram que nas dissertações e teses arroladas no banco da Coordenação de Aperfeiçoamento de Pessoal de Nível Superior (Capes) (2000 e 2001), a maior ocorrência é de trabalhos que não enfocam qualquer das tarefas do idoso ( $n=31,32 \%)$, vindo a seguir os que tratam dos arranjos físicos satisfatórios $(n=21,69 \%)$ e dos ajustes às perdas físicas e de saúde $(n=20,48 \%)$. As demais tarefas foram raramente consideradas. Há a necessidade de maior investimento em pesquisas sobre as várias tarefas.

\section{Considerações Finais}

Subjacente a todas as tarefas está a educação para o envelhecer, todavia essa é uma área que carece muito de pesquisas, embora existam, no Brasil, textos informativos diversos que podem ser de ajuda direta (Grinberg \& Grinberg, 1999) e pesquisas sobre quem educa os idosos (Cachioni, 2003).

Há carência de estudos experimentais e de pesquisas de avaliação dos programas disponíveis para os idosos e que os deveriam capacitar para as tarefas do envelhecer. Também é preciso pesquisar a educação informal.

Cumprir tais tarefas é importante, como é importante também que o idoso conte com o apoio da família, da sociedade e dos profissionais que atuam na área. Dessa forma, ele poderá ter uma velhice bemsucedida e usufruir do prazer de ser e de viver, contribuindo para o bem de todos.

\section{Referências}

Aalto, V., Pekuri, P., \& Seppae, K. (2002). Primary health care professionals'activity in intervening in patients'alcohol drinking perspective. Drug \& Alcohol Dependence, 66 (1),
Birren, J. E. (1980). Progress in research on aging in the behavioral and social sciences. Human Development, 23 (1), 33-45.

Bischof, J. L. (1976). Adult psychology. New York: Harper \& Row.

Cachioni, M. (2003). Quem educa os idosos? Um estudo sobre professors de universidade de terceira idade. Campinas: Alínea.

Chawla, S. (2003). Demographic aging and development. Generations, $17(1), 20-23$.

Grinberg, A., \& Grinberg, B. (1999). A arte de envelhecer com sabedoria. São Paulo: Nobel.

Havighurst, R. J. (1953). Human development andeducation. New York: David Mckay.

Johansson, B., Grand, J. D., Plamin, R., Petersen, N. L., Ahen, F., Berg, S., \& McClearn, G. E. (2001). Health Psychology, 20 (1), 33-40.

Johnson, J. E. (2002). Why rural olders drive against advice. Journal of Community Health Nursing, 19 (4): 237-244.

Kraaij, V., \& Garnefski, N. (2002). Negative life events and depressive symptoms in late life: Buffering effects of parent and partner bonding? Personal Relation Ships, 9 (2): 205-214.

Lichtenberg, P., MacNeill, S. E., Lysack, C. L., Bank, A. L., \& Neufeld, S. W. (2003). Predicting discharge and long-term outcome patterns for frail elders. Rehabilitation Psychology, 48 (1), 37-43.

Manly, J. J., Toreradji, P., Tang, M. X., \& Stern, Y. (2003). Literacy and memory decline amorng ethncally diverses elders. Journal of clinical and experimental neuropsychology, 25 (5), 680-690.

Melo, S. P. S. (1981). Tarefas de desenvolvimento do adulto e sua perspectiva de tempo: um estudo através de obras literárias nordestinas. Dissertação não-publicada, Universidade Federal da Paraíba, João Pessoa.

Neri, A. L., \& Freire, S. A. (Orgs.). (2000). Eporfalar em boa velhice. Campinas: Papirus.

Pfromm Netto, S. (1976). Psicologia da adolescência (3.ed.). São Paulo: Pioneira.

Rush, B. R., Urbanoski, K. A., \& Allen, B. A. (2003). Physicians'enquires into their patients' alcool use. Addiction, 98 (7), 895-900.

Santos, M. F., \& Almeida, A. M. O. (2002). Práticas sociais relativas ao idoso. Temas em Psicologia, 10 (3), 221-228.

Schooler, C., \& Mulatu, M. S. (2001). The reciprocal effects of leisure time actirities and intelectual functioning in older people: a longitudinal analysis. Psychology and Aging, 16 (3), 466-482.

Sweeney, M. A., \& Chiriboga, D. A. (2003). Evalueting the effectiveness of a multimedia program on home safety. Gerontologist, 43 (3), 325-334.

Wagman, J. B., \& Miller, D. B. (2003). Neted reciprocities: the organism-environment system in perception-action and development. Developmental Psychology, 42 (4), 317-334.

Witter, G. P., \& Maria, F. A. (2005). Velhice no banco de teses da CAPES (2000 e 2001). In G. P. Witter. Metaciência e psicologia (pp.172-184). Campinas: Alínea

Recebido para publicação em: 21/10/2004

Versão final reapresentada em: 11/5/2005

Aprovado em: 29/9/2005 